

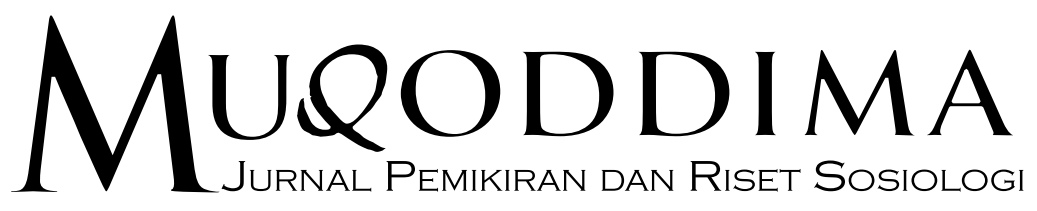




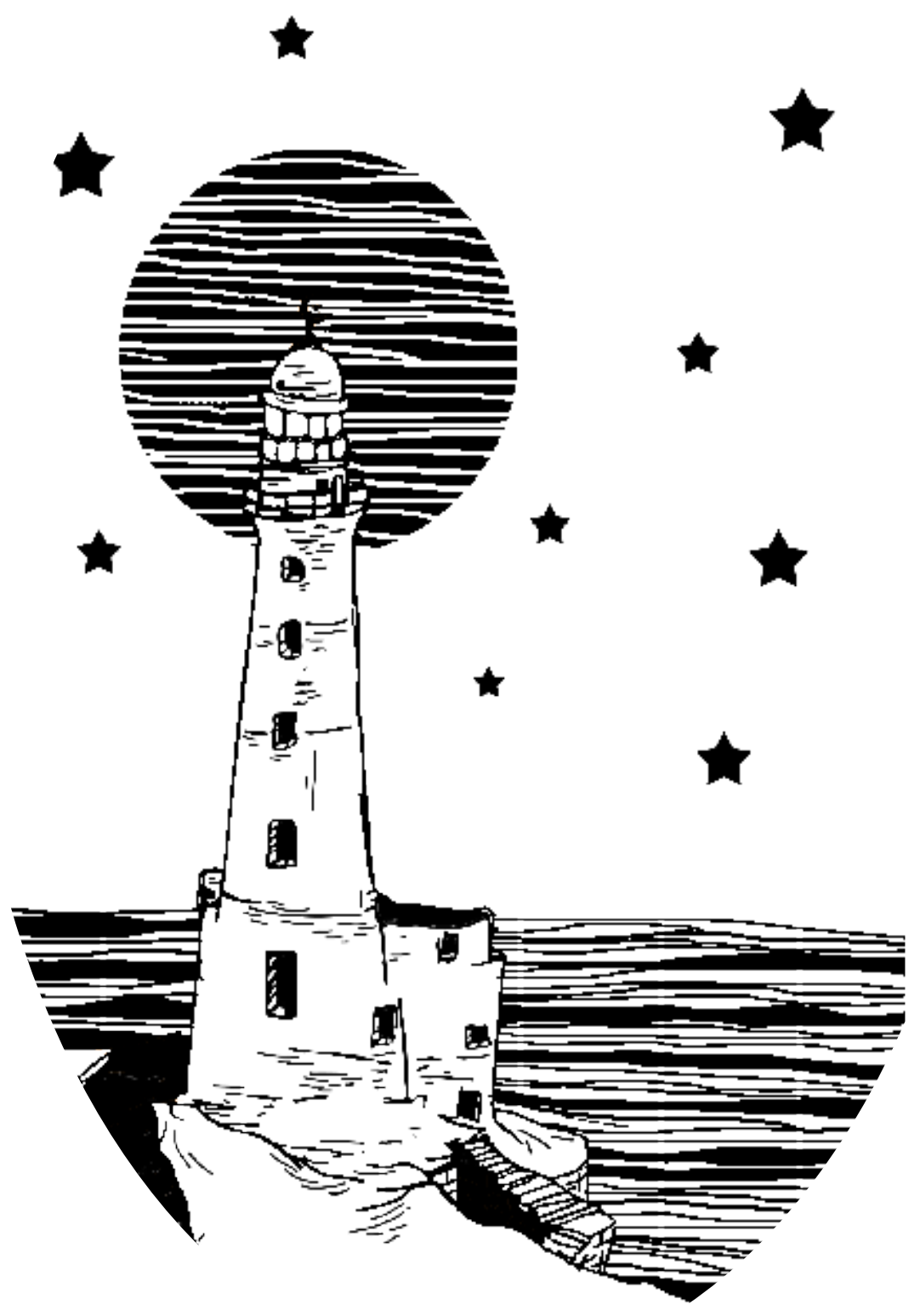




\section{MUgoddima \\ JuRnal PEMIKIRAN DAN RISET SOSIOLOGI}

Vol. 1 No. 2 Desember 2020

ISSN 2745-7168 (DARING)

\section{Editor in Chief}

Eneng Darol Afiah, Universitas Nahdlatul Ulama Indonesia Jakarta

\section{Managing Editor}

Naeni Amanulloh, Universitas Nahdlatul Ulama Indonesia Jakarta

\section{Editor}

Amsar A. Dulmanan, Universitas Nahdlatul Ulama Indonesia Jakarta

Pangeran P.P.A. Nasution, Universitas Malikussaleh

Muhammad Nurul Huda, Universitas Nahdlatul Ulama Indonesia Jakarta

Muhammad Mustafid, Universitas Nahdlatul Ulama Yogyakarta

Mujtaba Hamdi, Universitas Nahdlatul Ulama Indonesia Jakarta

Fikri Tamau, Universitas Pembangunan Nasional Veteran Jakarta

Hanifa Maulidia, Sekolah Tinggi Imigrasi

Dewi Anggraeni, Universitas Nahdlatul Ulama Indonesia Jakarta

Muhammad Nurun Najib, Universitas Nahdlatul Ulama Indonesia Jakarta

R.M. Joko P. Mulyadi, Universitas Nahdlatul Ulama Indonesia Jakarta

Moh. Faiz Maulana, Universitas Nahdlatul Ulama Indonesia Jakarta

\section{Reviewer}

Achmad Munjid, Universitas Gajah Mada, Yogyakarta, Indonesia

Ahmad Suaedy, Universitas Nahdlatul Ulama Indonesia, Jakarta, Indonesia

Syamsul Hadi, Universitas Nahdlatul Ulama Indonesia, Jakarta, Indonesia

Moh. Yasir Alimi, Universitas Negeri Semarang, Semarang, Indonesia

Nadiatus Salama, Universitas Islam Negeri Walisongo, Semarang, Indonesia

Anton Novenanto, Universitas Brawijaya, Malang, Indonesia

Akhmad Ramdhon, Universitas Sebelas Maret, Surakarta, Indonesia

Imam Ardhianto, Universitas Indonesia, Jakarta, Indonesia

Achmad Fawaid, Universitas Nurul Jadid, Probolinggo, Indonesia

Fariz Alnizar, Universitas Nahdlatul Ulama Indonesia, Jakarta, Indonesia

Pajar Hatma Indra Jaya, Universitas Islam Negeri Kalijaga, Yogyakarta, Indonesia

\section{Ilustrasi Cover}

'Menara Petunjuk', Shilfina Putri Widatama 
MUQODDIMA Jurnal Pemikiran dan Riset Sosiologi diterbitkan oleh Laboratorium Sosiologi, Departemen Sosiologi, Fakultas Sosial dan Humaniora, Universitas Nahdlatul Ulama Indonesia (UNUSIA) Jakarta. Jurnal ini terbit dua kali setahun, yaitu pada Juni dan Desember.

MUQODDIMA Jurnal Pemikiran dan Riset Sosiologi menyajikan karya-karya ilmiah di bidang sosiologi dan sosial humaniora. MUQODDIMA Jurnal Pemikiran dan Riset Sosiologi mengarahkan diri pada kajian sosial-keagamaan, budaya, politik-ekonomi, serta isuisu kemanusiaan dan lingkungan hidup baik yang dihasilkan dari penelitian lapangan maupun tinjauan kritis atas teori sosial. MUQODDIMA Jurnal Pemikiran dan Riset Sosiologi mengundang para akademisi dan peneliti di bidang sosial humaniora, khususnya sosiologi, serta para praktisi/aktivis sosial untuk mengirimkan karyanya.

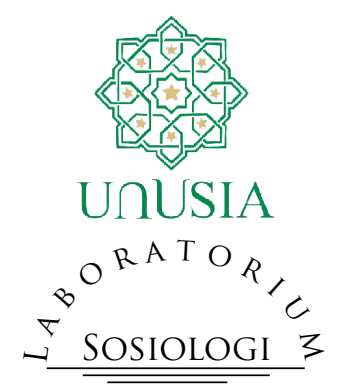

\author{
Alamat Editorial: \\ Kampus UNUSIA Jakarta \\ Jl. Taman Amir Hamzah No. 5 \\ Jakarta Pusat 10430 \\ Telp/Fax: (021) 3156864 / 3906501 \\ E-mail: muqaddima.jms@unusia.ac.id \\ Website: http://journal.unusia.ac.id/index.php/Muqoddima
}




\section{MUgODdima \\ JuRnal Pemikiran dan Riset Sosiologi}

Vol. 1 No. 2 Desember 2020

\section{DAFTAR IsI}

\section{Pengantar Editorial}

\begin{tabular}{l|l}
$\mathrm{i}-\mathrm{x}$ & $\begin{array}{l}\text { ENENG DAROL AFIAH } \\
\text { Membaca Ulang 'Guncangan Besar' Francis Fukuyama }\end{array}$
\end{tabular}

\section{Artikel}

$113-132$

Rachmad K. Dwi Susilo

Sosiologi Sebagai the Queen of Social Sciences: Sebuah Refleksi

Taufik Hidayadi \& Henny Saptatia Drajati Nugrahani

Stereotip Warga Tionghoa

dalam Geopolitik Hubungan Indonesia dengan Tiongkok

$145-164$

FARIZ ALNIZAR

Antara Iman dan Kenikmatan:

Konstruksi Gagasan Pascamodernisme Ariel Heryanto

$165-180$

NANA KRISTIAWAN

Dinamika Pengelolaan Sumber Daya Air di Situ Kemuning, Cimanggis Kabupaten Bogor

$181-196$

INDHAR WAHYU WiRA HARJO

Konsolidasi Demokrasi Melalui Liga Santri Nusantara

197-210 MoH. Faiz MaUlana

Dangdut Koplo: Tubuh, Seksualitas, dan Arena Kekuasaan Perempuan

$211-230$

ELMY BONAFITA ZAHRO

Smoking Outcome Expectancy: Pengetahuan, Perilaku, dan Konsekuensi Merokok

\section{TelaAh Buku}




\title{
Konsolidasi Demokrasi Melalui Liga Santri Nusantara
}

\author{
Indhar Wahyu Wira Harjo \\ Jurusan Sosiologi Universitas Brawijaya \\ E-mail: indhar.wahyu@ub.ac.id
}

\begin{abstract}
Abstrak
Penelitian ini mengulas relasi antara organisasi masyarakat sipil/civil society organization (CSO) dengan pemerintah dalam upaya memperkuat praktik demokrasi. Tujuan telaah itu untuk memperlihatkan bahwa CSO dan pemerintah telah berkolaborasi dalam konsolidasi demokrasi melalui pembangunan olahraga. Penelitian ini menggunakan metode penelitian kualitatif dengan pendekatan analisis wacana kritis. Hasil penelitian memperlihatkan bahwa Liga Santri Nusantara (LSN) merupakan bentuk pembinaan potensi olahraga bagi para santri di Tanah Air. Selainitu, kompetisi sepak bola itu juga menjadi sarana bagi Rabithah Ma' ahid Islamiah Nahdlatul Ulama (RMI NU) dan Nahdlatul Ulama (NU) untuk berpartisipasi dalam konsolidasi demokrasi di Indonesia. Penyelenggaraan LSN menjadi bentuk dari konsolidasi demokrasi di Indonesia dalam tiga aspek penting. Pertama, konsolidasi itu berlangsung dalam aspek partisipasi terhadap perumusan kebijakan penyelenggaraan LSN, kedua dalam hal implementasi kebijakan penyelenggaraan LSN, dan ketiga dalam pembentukan saluran aspirasi bagi RMI NU dan NU. Konsolidasi demokrasi itu menyisakan hambatan dan tantangan setelah dalam pelaksanaan LSN terdapat miskoordinasi dan misadministrasi. Partisipasi CSO dalam program pembangunan pemerintah ternyata tidak serta-merta berperan penting bagi konsolidasi demokrasi. Partisipasi CSO yang sesuai dengan regulasi dan kewenangan justru menempati kedudukan lebih penting daripada sekadar keterlibatan yang malah melemahkan praktik demokrasi di Tanah Air.
\end{abstract}

Kata Kunci: civil society, sepak bola, pesantren, kemenpora, olahraga, analisis wacana kritis 


\begin{abstract}
The present study investigates the relation between civil society organization (CSO) and government in dealing with the attempts to strengthen democratic practice. The aim of the study is to illustrate that CSO and government has collaborated in democratic consolidation through sports development. The study implemented qualitative research method with the approach of critical discourse analysis. The result of the study revealed that Liga Santri Nusantara (LSN - Indonesian Students' League) was a type of sport trainings for potential students in Indonesia. In addition, the football competition was also a means for Rabithah Ma'ahid Islamiah Nahdlatul Ulama (RMI NU) and Nahdlatul Ulama (NU) to participate in democratic consolidation in Indonesia. LSN was a form of democratic consolidation in Indonesia that encompassed three key aspects. First, the consolidation took place on the aspect of participation in formulating the policy of how to manage the performance of LSN, the second was on the implementation of the policy, and the last was on the forming room for RMI NU's and NU's ideas. The democratic consolidation left some hurdles and challenges while there was a miscoordination and misadministration. The CSO participation in government's development programs did not simply play a prominent role for the democratic consolidation. The participation that obeyed the regulations and authorities had a significant position that was way more important than any involvement that even weakened the practice of democracy in Indonesia.
\end{abstract}

Keywords: civil society, football, boarding school, Ministry of Youth and Sports Affairs, sports, critical discourse analysis

\title{
Pendahuluan
}

Liga Santri Nusantara (LSN) bukan hanya merupakan praktik pembinaan olahraga sepak bola usia muda, tetapi juga merupakan gugatan atas peminggiran negara terhadap pesantren. LSN menjadi wadah bagi peneguhan eksistensi pesantren di Indonesia melalui kompetisi sepak bola. Tidak mengherankan apabila pada setiap penyelenggaraan LSN tahun ketiga penyelenggaraan LSN antusias para peserta selalu mengalami peningkatan. Pada tahun pertama penyelenggaraan kompetisi itu terdapat 280 kesebelasan berpartisipasi. Angka itu terus meningkat hingga tercatat sebanyak 1.049 pesantren dari 34 provinsi yang terlibat di kompetisi tersebut pada tahun 2018. Menteri Pemuda dan Olahraga (Menpora) pada waktu itu, Imam Nahrawi, menyatakan bahwa LSN penting untuk menjadi wadah bagi para santri agar dapat menjadi atlet yang mengharumkan nama bangsa (Bachrain 2017; Firdaus 2017). Kondisi-kondisi ini memperlihatkan bahwa LSN sebagai fenomena sosial yang penting untuk diteliti.

Penelitian mengenai olahraga sebagai alat untuk memperkuat praktik demokrasi telah dilakukan para akademisi. Kategori penelitian yang pertama merupakan riset yang berhasil memperlihatkan perlawanan kelompok sosial dalam memperjuangkan identitasnya di hadapan negara, seperti identitas ras, jenis kelamin dan orientasi seksual (Claringbould dan Knoppers 2008; Griffin 
2012; Towler, Crawford, dan Bennett 2020). Penelitian Pat Griffin sebagai contoh, menunjukkan sejumlah tantangan dan hambatan untuk memperjuangkan kesamaan kedudukan kelompok lesbian, gay, bisexual, dan transgender (LGBT) di sektor olahraga. Kategori penelitian kedua memuat penelitian-penelitian yang melakukan perubahan sosial menggunakan olahraga (Giulianotti et al. 2019; Kaufman dan Wolff 2010). Penelitian dalam kategori ini salah satunya dilakukan Richard Giulianotti, riset itu memperlihatkan penggunaan olahraga sebagai instrumen untuk membangun perdamaian antarkomunitas yang berlainan. Kategori ketiga berisi riset-riset yang telah menunjukkan mengenai keberhasilan olahraga sebagai sarana untuk menolak atau mendukung sebuah kebijakan negara (Giulianotti 2011; Kilcline 2017). Riset dalam kategori ini menunjukkan bahwa olahraga berperan penting dalam memberikan peluang bagi protes-protes yang dilakukan masyarakat sipil terhadap berbagai kebijakan negara. Penelitian Chatal Kilcine misalnya, memperlihatkan protes terhadap kebijakan negara dalam menyelenggarakan event olahraga raksasa dalam kaitannya dengan faktor ekonomi, lingkungan dan masalah sosial. Pemetaan terhadap ketiga kategori tersebut di atas memperlihatkan aspek yang masih luput dari kajian akademisi, yaitu upaya untuk memperkuat demokrasi melalui kompetisi olahraga.

Penelitian ini berusaha untuk berkontribusi dengan jalan memberikan sumbangan ulasan mengenai konsolidasi demokrasi melalui kompetisi olahraga yang melibatkan lembaga pendidikan berbasis agama. Tulisan ini didasarkan pada argumen bahwa LSN merupakan sebuah praktik untuk memperkuat praktik demokrasi di Indonesia. LSN merupakan sebuah usaha untuk memberikan ruang bagi pesantren agar dapat terlibat dalam pembangunan olahraga di Indonesia. Argumen tersebut akan diperlihatkan melalui sejumlah bukti pendukung yang telah dikumpulkan selama penelitian berlangsung.

\section{Metode}

Riset ini menggunakan metode penelitian kualitatif dengan pendekatan analisis wacana kritis (AWK). Salah satu kekuatan pendekatan AWK berada dalam kemampuannya untuk mengulas masalah sosial dengan jalan memperlihatkan bagaimana wacana memproduksi atau mereproduksi dominasi sosial. Selain itu, analisis wacana kritis juga membuka peluang untuk memperlihatkan perlawanan terhadap dominasi yang telah mapan (van Dijk 2001:96; Haryatmoko 2016:79). Keunggulan itulah yang dimanfaatkan dalam penelitian ini untuk menunjukkan proses pertarungan wacana dengan tujuan memperkuat praktik demokrasi di Indonesia. AWK dalam penelitian ini mengacu kepada model Teun van Dijk yang menghubungkan diskursus dengan kognitif dan masyarakat (van Dijk 2001:97).

Peneliti menggunakan teknik pengumpulan data studi dokumen untuk menghubungkan diskursus, kognitif dan masyarakat. Dokumen dalam riset ini berupa rekaman pembukaan LSN tahun 2017, unggahan Instagram akun LSN, artikel berita LSN di media massa online, Undang-Undang, Peraturan Pemerintah, artikel jurnal, dan buku yang relevan dengan topik penelitian. Dokumen-dokumen itu dikumpulkan kemudian dipilah dan dipilih berdasarkan teknik penentuan 
sumber data yang dilakukan secara saksama.

Pemilihan sumber-sumber data dalam riset ini menggunakan teknik kritik ekstern dan intern. Kritik ekstern berkaitan dengan penyaringan dokumen dengan pertanyaan apakah dokumen itu otentik, siapa pembuatnya, bagaimana bahasa dan bentuknya serta dari mana sumbernya. Sedangkan kritik intern berkaitan dengan pertanyaan tentang apakah isi dokumen tertentu dapat diterima sebagai kenyataan (Kartodirdjo 1997:59). Melalui teknik-teknik itulah data dalam penelitian ini diperoleh dan diolah untuk memperoleh simpulan penelitian.

\section{Diskusi dan Analisis}

\section{Kick off LSN}

LSN merupakan kompetisi sepakbola yang melibatkan peserta dari berbagai pondok pesantren yang berada di Indonesia. Pondok pesantren dalam konteks ini mencakup pusat-pusat kegiatan keislaman yang disebut pesantren di Jawa dan Kalimantan Selatan; pondok di Kalimantan, Sulawesi Selatan, dan sebagian Sumatra; Dayah di Aceh; dan surau di Sumatera Barat (Azra, Afrianty, dan Hefner 2007:288; Priyatna 2020:25). Kompetisi itu pertama kali dilaksanakan pada tahun 2015 di bawah pengelolaan Kementrian Pemuda dan Olahraga (Kemenpora). Di tahun pertama penyelenggaraan kompetisi tersebut, Kemenpora menjadi penyelenggara tunggal. Selanjutnya pada tahun kedua pelaksanaan LSN Kemenpora bekerja sama dengan Rabithah $M a^{\prime}$ ahid Islamiah Nahdlatul Ulama (RMI $\mathrm{NU}$ ), yaitu asosiasi pondok pesantren seluruh Indonesia yang berafiliasi dengan organisasi kemasyarakatan Nahdlatul Ulama (NU).

LSN berlangsung sebagai tindak lanjut dari kerja sama antara Kemenpora dengan NU.Kolaborasi kedualembaga tersebutsetelahterdapat Nota Kesepahaman antara Ketua Pengurus Besar NU (PBNU) dengan Menpora Republik Indonesia di Pondok Pesantren Mabaul Maarif Denanyar, Jombang Jawa Timur, Selasa 4 Agustus 2015 (Kurniawan 2015). Nota kesepahaman itu juga menjadi awal dari kewenangan RMI NU sebagai operator LSN pada tahun 2016, dengan pendanaan yang berasal dari anggaran Kemenpora. Pada pelaksanaan LSN 2017, terungkap dana yang dianggarkan Kemenpora sebesar delapan miliar rupiah.

Jumlah peserta LSN selalu mengalami perubahan dari waktu ke waktu. Kompetisi sepak bola itu melibatkan 280 kesebelasan di tahun pertama penyelenggaraannya. Jumlah peserta itu melonjak tajam di tahun 2016 menjadi sebanyak 830 tim yang berpartisipasi. Setahun berikutnya jumlah tim yang bersaing di liga itu bertambah menjadi 1.024 kesebelasan. Di tahun 2018 jumlah tim yang berlaga dalam kompetisi tersebut sebanyak 1.049 tim. Jumlah peserta itu mengalami penurunan di tahun 2019 menjadi 800 kesebelasan saja (Arifa, Puji, dan Humas Jateng 2018; Jabbar 2019). Sedangkan penyelenggaraan liga itu pada tahun 2020 ditunda pelaksanaannya sebagai imbas dari pandemi Covid-19 yang merajalela di Nusantara.

Sistem pelaksanaan LSN terbagi ke dalam dua tingkatan, yaitu level regional dan level nasional. Tingkatan pertama disebut sebagai region, pada tahun ketiga 
penyelenggaraan LSN terdapat 32 region yang tersebar di 34 provinsi di seluruh Indonesia. Di region-region itu perwakilan dari 23.000 Pondok Pesantren yang berada dikoordinir RMI melangsungkan pertandingan untuk memperebutkan tiket di level nasional. Kick off liga diselenggarakan di wilayah luar Jawa, selanjutnya seri nasional pelaksanaannya berlangsung di Pulau Jawa. Pada tingkat nasional hanya tersisa 32 kesebelasan yang berlaga untuk memperoleh predikat sebagai Juara LSN.

Proses untuk menentukan kesebelasan yang menjadi Juara LSN memerlukan fase yang panjang. LSN harus melangsungkan 1.032 pertandingan di tingkat region dan nasional untuk menentukan juara pertama. Secara rinci terdapat 992 pertandingan di babak penyisihan (pertandingan di tingkat region) dan 40 pertandingan di seri nasional. Jumlah pertandingan sebanyak itu menempatkan LSN sebagai liga sepak bola terbesar di Indonesia.

Kompetisi sepakbola sebesar itu diselenggarakan dengan tujuan yang telah ditentukan. Tujuan penyelenggaraan LSN itu tampak dari slogan yang diusung: 'Dari pesantren untuk Negara Kesatuan Republik Indonesia (NKRI)'. Berdasarkan slogan itu, LSN diproyeksi untuk menjadi wadah bagi santri agar dapat berkontribusi bagi NKRI. Secara praktis, penyelenggaraan LSN diarahkan sebagai ajang untuk mengelola potensi para santri di bidang olahraga.

\section{Urgensi Penyelenggaraan LSN}

Penyelenggaraan LSN berdasarkan slogan 'Dari pesantren untuk Negara Kesatuan Republik Indonesia (NKRI)' mengarah kepada upaya memfasilitasi pengembangan pondok pesantren dalam bidang sepak bola. Penjelasan mengenai tujuan penyelenggaraan LSN diberikan oleh para aktor sentral kompetisi ini di acara launching pada tahun 2017. Acara itu merupakan acara yang penting sebab menghadirkan Menpora, Ketua PBNU, inisiator LSN, dan Ketua Penyelenggara LSN yang sekaligus menjabat sebagai Ketua RMI. Dalam kegiatan itu para aktor tersebut terdapat penjelasan mengenai asal mula penyelenggaraan LSN.

Penyelenggaraan LSN di tahun 2015 tidak terlepas dari inisiasi yang diawali oleh Muhaimin Iskandar (Cak Imin). Pada saat itu, Muhaimin menduduki jabatan sebagai Ketua Umum Partai Kebangkitan Bangsa. Muhaimin menyampaikan bahwa gagasan penyelenggaraan LSN bermula dari kegelisahannya saat melihat kondisi persepakbolaan di Tanah Air. Permasalahan itu dipandang Muhaimin perlu segera diselesaikan dengan solusi yang melibatkan santri.

Persepakbolaan Indonesia pada waktu itu menurut Muhaimin kerap menghadapi permasalahan. Permasalahan persepakbolaan tersebut meliputi problematika yang berkaitan dengan kualitas pemain dan pertandingan sepak bola, maupun penyelenggaraan kompetisi sepak bola di tingkat nasional. Kualitas pemain sepak bola Indonesia dipandang bermasalah terkait dengan kaliber keterampilan olah bolanya yang masih kalah apabila dibandingkan dengan pemain-pemain dari negara tetangga seperti Malaysia dan Thailand. Selain itu, Muhaimin juga menyoroti tentang konflik antarsuporter yang kerap terjadi sepanjang penyelenggaraan kompetisi sepak bola di Tanah Air. Terlebih lagi 
sumber rekutmen pemain sepak bola untuk atlet profesional yang berkualitas juga menjadi kendala besar di Tanah Air.

Muhaimin menjelaskan penyelenggaraan LSN di Indonesia digagas juga berkaitan dengan aspek di luar pembinaan sepak bola. Pertama, penyelenggaraan LSN menjadi salah satu cara untuk memperkenalkan pesantren ke khalayak. Pondok pesantren memiliki sumber daya yang besar dalam menghasilkan santri yang memiliki potensi di bidang agama, sains, teknologi dan juga olahraga. Kedua, Muhaimin menengarai tidak ada pengelolaan yang sistematis dari Kementrian Agama dan Kementrian Pendidikan dan Kebudayaan terhadap pesantren di sektor olahraga. Potensi santri yang berlimpah secara kuantitas dan kualitas masih perlu dikelola Kemenpora mengingat dua institusi pendidikan yang lain belum memiliki program terencana untuk pengembangan sepak bola di pondok pesantren.

Menpora Imam Nahrawi sebagai Menpora pada waktu itu menindaklanjuti gagasan Muhaimin dengan menggelar LSN sebagai rangkaian perayaan Hari Santri Nasional tahun 2015. Imam menyampaikan bahwa LSN harus diselengarakan secara rutin agar potensi santri pondok pesantren bisa bangkit dan terlibat dalam tanggung jawab mengibarkan Sang Saka Merah Putih melalui sepak bola. Hal itu selaras dengan slogan dari LSN 'Dari Pesantren untuk NKRI'. Secara konkret, Kemenpora secara mandiri menyelenggarakan kompetisi sepak bola antarpondok pesantren pada tahun 2015 dan selanjutnya bekerja sama dengan RMI di tahun 2016.

Pernyataan Menpora pada waktu itu selaras dengan penjelasan dari Ketua Panitia Nasional LSN, Abdul Ghofarrozin (Gus Rozin). Abdul menyampaikan bahwa maksud dari penyelenggaraan LSN adalah sebagai wadah bagi santri untuk mengembangkan potensinya di bidang sepak bola. Lebih lanjut, Abdul juga menyampaikan bahwa LSN juga menjadi cikal bakal bagi kelahiran para pemain sepak bola profesional di Tanah Air. Untuk memperkuat keyakinan itu, Abdul menyebutkan pula nama Muhammad Rafli Mursalim sebagai pemainpemain berprestasi di LSN yang berhasil masuk di dalam Tim Nasional Indonesia kelompok usia di bawah 19 tahun.

Penyelenggaraan LSN yang berorientasi kepada pencarian bakat santri yang piawai bermain sepak bola untuk kepentingan Tim Nasional Indonesia juga menjadi perhatian bagi Ketua PBNU, K. H. Said Agil Siraj. Pernyataan tersebut dapat dicermati dalam kutipan berikut ini:

“Tadi sudah disinggung oleh Pak Mentri bahwa kita semua sedih, kita semua prihatin kalau hanya gara-gara permainan olahraga sampai ada korban. Siapa namanya yang mati dua hari yang lalu Andrean ya. Jangan sampai terjadi di tengah-tengah LSN. Tunjukkan kita tidak seperti mereka, kita punya kelebihan. Insyaallah ke depan akan menghasilkan pemain-pemain yg profesional, masak dari berapa santri, 67 juta 4 juta yang santri masak cari 11 aja tidak ada pasti ada 11 aja kok."

Pernyataan Said memperlihatkan bahwa LSN menjadi kompetisi yang berpotensi menghasilkan pemain-pemain sepak bola profesional dari santri pondok pesantren. 
Pernyataan Said juga memperlihatkan bahwa penyelenggaraan LSN berhubungan pula dengan aspek di luar sepak bola. Dari pernyataan di atas tampak bahwa Said menempatkan LSN sebagai pembeda antara pemain sepak bola santri dengan bukan santri. Said menjelaskan karakter santri yang tangguh, kokoh, tegar, tapi tetap ber-akhlakul karimah. LSN menurut Said pada dasarnya memperkuat pembangunan karakter kepribadian dan jati diri bangsa Indonesia terutama umat Islam khususnya warga NU. Penyelenggaraan LSN maka dari itu bukan sekedar pembentukan wadah bagi santri untuk mengembangkan potensi sepak bola, namun juga untuk pembentukan karakter bangsa.

Para aktor sentral dalam penyelenggaraan LSN memiliki variasi pandangan terhadap penyelenggaraan kompetisi sepak bola tersebut. Pada saat launching LSN 2017, sejumlah tokoh itu memberikan pandangannya masing-masing terkait tujuan penyelenggaraan LSN. Perbedaan pandangan itu terjadi antara Menpora, Ketua PBNU, Inisiator LSN dan Ketua Penyelenggara LSN yang sekaligus menjabat sebagai Ketua RMI. Variasi cara pandang itu secara rinci dapat diamati di tabel berikut ini:

Tabel 1

Perbedaan Cara Pandang Terhadap Penyelenggaraan LSN

\begin{tabular}{c|r|l}
\hline Nama & Kedudukan & \multicolumn{1}{|c}{ Pemikiran tentang Tujuan LSN } \\
\hline Abdul Ghofarrozin & $\begin{array}{r}\text { Ketua Panitia } \\
\text { Nasional LSN/Ketua } \\
\text { RMI NU }\end{array}$ & $\begin{array}{l}\text { Kita mempunyai lebih dari dua } \\
\text { juta kader yang bisa dicari sebagai } \\
\text { kader pemain sepak bola nasional. }\end{array}$ \\
\hline Muhaimin Iskandar & Inisiator LSN & $\begin{array}{l}\text { Sumber daya manusiaituberlimpah } \\
\text { di kalangan pesantren. Pesantren } \\
\text { yang tua juga belum banyak } \\
\text { diketahui oleh banyak pihak punya } \\
\text { bibit-bibit berbagai bidang: ilmu } \\
\text { agama, sains dan teknologi, dan } \\
\text { tentu saja bibit pemain olahraga. }\end{array}$ \\
\hline Imam Nahrawi & Menpora \\
& (periode 2014-2019) & $\begin{array}{l}\text { Agar potensi santri pondok } \\
\text { pesantren betul-betul bisa bangkit } \\
\text { dan bisa terlibat secara penuh dalam } \\
\text { tanggung jawab mengibarkan } \\
\text { Sang Saka merah putih lewat } \\
\text { sepakbola. }\end{array}$ \\
\hline Said Agil Siraj & Ketua Umum PBNU \\
\hline & $\begin{array}{l}\text { Tunjukkan bahwa ber-LSN ini } \\
\text { kita mampu menunjukkan } \\
\text { kepada pihak lain kita ini Islam } \\
\text { yg damai, Islam yang berakhlak, } \\
\text { Islam yang jauh dari radikalisme } \\
\text { apalagi sampai terorisme melalui } \\
\text { persepakbolaan ini' }\end{array}$ \\
\hline
\end{tabular}

Sumber: pidato launching LSN 2017.

Tabel 1 memperlihatkan bahwa para aktor sentral tersebut di atas memiliki tujuan tertentu pada saat terlibat dalam penyelenggaraan LSN. LSN di satu sisi merupakan wadah bagi santri untuk mengembangkan keterampilan dan potensinya di bidang olahraga. Di sisi lain, para aktor sentral itu juga berpikir 
bahwa LSN merupakan ajang pembentukan karakter-karakter yang penting bagi santri dan warga negara melalui kompetisi sepak bola.

\section{Relasi Civil Society dan Negara dalam LSN}

Uraian di bagian sebelumnya memperlihatkan mengenai LSN, penyelenggaraan dan tujuan yang hendak disasar. LSN merupakan kompetisi sepakbola yang diselenggarakan Kemenpora bekerja sama dengan RMI NU. Kompetisi tersebut melibatkan ribuan tim sepak bola dari pondok pesantren di seluruh Indonesia. Kompetisi itu menjadi wadah bagi pengembangan potensi para santri dalam bidang sepak bola sekaligus instrumen untuk menanamkan karakterkarakter tertentu. Uraian mengenai sejumlah aspek tersebut memperlihatkan urgensi LSN untuk diulas lebih lanjut di bagian ini.

Kolaborasi antara RMI NU, NU dengan Kemenpora dalam menyelenggarakan LSN memperlihatkan kerja sama yang dilakukan antara organisasi masyarakat sipil atau civil society organization (CSO) dengan negara. CSO dalam konteks ini mengacu kepada lembaga yang kedudukannya berada di antara keluarga dan negara; memfasilitasi kepentingan-kepentingan privat, publik dan bersifat suka rela; serta membatasi intervensi pemerintah dan negara (Bruce dan Yearly 2006:33; Diamond 1994:5; Hadi 2010:118; Usman 2002:382). RMI NU dan NU memenuhi kriteria-kriteria itu sehingga dapat dikategorikan sebagai CSO.

Hubungan CSO dengan negara yang bersifat kolaboratif semacam tampak dalam LSN merupakan fenomena menarik. Pada konteks Indonesia, kerja sama semacam ini tidak ditemukan sebelum Reformasi. Di masa itu, CSO kerap menempati kedudukan sebagai kelompok yang dihadap-hadapkan dengan militer. Kelompok militer, melalui implementasi Dwi Fungsi ABRI, menjadi kepanjangan tangan dari rezim Orde Baru. Pemerintah 'militer' Orde Baru itulah yang banyak ditentang oleh masyarakat sipil, terutama mahasiswa (Fakih 1999:2-3).

CSO menempati posisi penting di masa transisi Orde Baru menuju Reformasi. Pada masa yang disebut sebagai transisi demokrasi, CSO menempati kedudukan utama dalam menggulingkan rezim-rezim otoriter. Proses penggulingan rezim itu meliputi aksi protes, demonstrasi dan berbagai unjuk rasa di jalanan (Hadiwinata 2005:4). Pada masa Reformasi, para mahasiswa menjadi inisiator bagi gerakan masyarakat untuk menggulingkan rezim Orde Baru setelah berkuasa selama 32 tahun itu. Setelah rezim otoraritarian pimpinan Soeharto berhasil digulingkan, Era Reformasi memperlihatkan relasi antara CSO dengan negara yang memiliki pola berbeda.

Relasi antara CSO dengan negara pada masa Reformasi dan pasca-Rreformasi mengalami perubahan. Pola hubungan antara CSO dengan negara bukan lagi bersifat yang dominatif, seperti pada saat negara mendesak semua organisasi menerima asas tunggal Pancasila dan partai politik keislaman melebur ke dalam Partai Persatuan Pembangunan (Hefner 1993:32). Relasi antara CSO dengan negara berlangsung secara sejajar dengan ciri khas kerap terjadi ketegangan (tension) di antara keduanya. Dengan ketegangan semacam itu, resistensi masyarakat sipil terhadap negara relatif tinggi intensitasnya. Akan tetapi, negara tentu saja masih 
belum lupa dengan cara represif untuk menangani resistensi semacam itu (Imam 2007:42). Perubahan pola itu juga memungkinkan terjadinya perebutan pengaruh antara negara, pasar dan CSO yang mendekati kedudukan seimbang satu sama lain (Harjo 2019:43).

Relasi antara CSO dengan negara yang bersifat sejajar tampak dalam konteks pembangunan Pasca-Orde Baru. Negara mulai melibatkan CSO dalam kebijakankebijakan politik dan implementasi kebijakan selepas rezim otoritarian Soeharto. Keterlibatan CSO dalam pengambilan kebijakan dan praktik desentralisasi merupakan pilar utama dalam reformasi pemerintahan, terutama di negara-negara sedang berkembang seperti Indonesia (Ito 2011:413-14). Praktik semacam itulah yang sedang kita saksikan dalam penyelenggaraan LSN sebagai bentuk kolaborasi antara RMI NU, NU dengan Kemenpora.

Kolaborasi antara CSO semacam RMI NU dan NU bersama pemerintah dalam posisi yang sejajar merupakan aspek yang penting di dalam negara demokrasi. Keberadaan CSO merupakan bagian penting dari proses konsolidasi demokrasi (Linz 1996:7). Konsolidasi demokrasi merupakan proses penggabungan sejumlah elemen untuk memfasilitasi demokrasi meluas di berbagai segi kehidupan, sehingga warga negara tidak berkeinginan mengganti sistem ini dengan model pemerintahan yang lain (Diamond 1994:15; Nugroho 2001:26). Dengan demikian, kolaborasi antara CSO dan pemerintah itu pada prinsipnya merupakan sebuah proses untuk memperkuat praktik demokrasi di Indonesia.

Kolaborasi penyelenggaraaan LSN yang melibatkan RMI NU, NU dan Kemenpora dapat memperkuat demokrasi di Indonesia tampak setidaknya dari tiga aspek utama. Ketiga aspek itu antara lain perumusan kebijakan, pelaksanaan kebijakan, dan membuka jalur untuk menyalurkan kepentingan kepada pemerintah. Keterlibatan CSO semacam RMI NU dan NU dalam pembinaan sepak bola di Tanah Air itu meningkatkan partisipasi masyarakat dalam perencanaan dan pelaksanaan program pembangunan pemerintah. Partisipasi CSO itulah yang dapat memperkuat jalannya demokrasi di Indonesia.

Pertama, konsolidasi demokrasi tampak pada konteks keterlibatan RMI NU dan NU dalam merumuskan kebijakan penyelenggaraan LSN. Ketiga lembaga itu melakukan kolaborasi untuk menentukan regulasi yang berkaitan dengan penyelenggaraan LSN. Regulasiitu mengatur ketentuan mengenai peserta, operator liga, sampai ke jadwal pertandingan. Kerja sama semacam itu tidak mungkin terjadi pada rezim Orde Baru, sebab semua keputusan berada di tangan negara. CSO di masa itu tidak memiliki ruang untuk merumuskan kebijakan bersama-sama negara. Imbasnya negara menjadi dominan dalam proses perumusan kebijakan. Parisipasi CSO dalam perumusan kebijakan semacam itu yang membedakan proses perumusan kebijakan di masa Orde Baru dan setelahnya.

Partisipasi CSO dalam perumusan kebijakan dapat memperkuat demokrasi di Indonesia. Keterlibatan dalam perumusan kebijakan membuka peluang bagi CSO untuk melakukan pengawasan agar tidak terjadi penyalahgunaan wewenang dan pemusatan kekuasaan serta mendorong partisipasi masyarakat sipil dalam melakukan pengawasan terhadap negara (Mercer 2002:8). Partisipasi dalam 
merumuskan kebijakan pembinaan sepak bola terhadap santri pondok pesantren telah meningkatkan keterlibatan RMI NU dan NU dalam melakukan pengawasan terhadap pemerintah agar tidak menyalahgunakan wewenang.

Kedua, konsolidasi demokrasi juga terjadi pada saat RMI NU menjalankan kebijakan pembinaan sepakbola para santri. RMI NU menempati posisi penting sebagai operator liga yang menyelenggaraan lebih dari seribu pertandingan di seluruh Nusantara. Terlebih lagi, RMI NU juga melibatkan ribuan pondok pesantren yang berada di bawah koordinasinya untuk terlibat dalam kompetisi sepakbola LSN. Keterlibatan RMI NU dengan cara itu merupakan bentuk konkret dari pelaksanaan kebijakan pembinaan sepak bola di lembaga pendidikan Indonesia.

Ketiga, partisipasi RMINU dan NU dalam membuka jalur untuk menyalurkan kepentingan merupakan bentuk penguatan demokrasi. RMI dan NU melalui keterlibatannya dalam penyelenggaraan LSN menjadi salah satu cara untuk mendesakkan kepentingannya. Pondok pesantren menempati posisi pinggiran dan dipandang tidak setara dengan sekolah formal sejak masa pendudukan Belanda (Syarif 2019:117). Kondisi inilah yang sedang diubah melalui kompetisi sepakbola bertajuk LSN. Keikutsertaan RMI NU dalam mengelola LSN menjadi salah satu cara untuk mencapai kepentingan kelompok asosiasi pondok pesantren yang berafiliasi dengan NU.

Partisipasi LSN sebagai strategi untuk mencapai kepentingan tertentu terlihat dari pernyataan Ketua RMI dan Ketua PBNU. Pada saat peluncuran LSN 2017 keduanya memberikan penjelasan bahwa kompetisi sepak bola itu lebih dari ajang untuk mengembangkan potensi santri di bidang olahraga saja. Pernyataan tersebut dapat dicermati dalam kutipan-kutipan berikut ini:

“Tunjukkan bahwa ber-LSN ini kita mampu menunjukkan kepada pihak lain kita ini Islam yg damai, Islam yang berakhlak, Islam yang jauh dari radikalisme apalagi sampai terorisme melalui persepakbolaan ini" (Said Agil Siraj-Ketua Umum Tanfidziyah PBNU).

"Kami menaungi lebih dari 23 ribu pesantren dari $28 \mathrm{rb}$ pesantren seluruh Indonesia. Yang ada di bawah RMI itu ada 23rb pesantren, dengan jumlah santri lebih dari 4 juta orang. Ini ya yang cukup banyak dan dari 4 juta orang itu saya kira lebih dari 2 juta diantaranya adalah santri laki-laki. Berarti kita mempunyai lebih dari 2 juta kader yang bisa dicari sebagai kader pemain sepak bola nasional. Ini jumlah yang saya kira luar biasa" (Abdul Ghofarrozin- Ketua Panitia Nasional LSN/ Ketua RMI NU).

Pernyataan Said di atas memperlihatkan LSN sebagai salah satu cara untuk menunjukkan bahwa NU memiliki karakter yang berbeda dengan kelompok lain. Sedangkan pernyataan Abdul menunjukkan 'kekuatan' yang dimiliki RMI dalam hal jumlah sumber daya manusia yang dikelola. Pernyataan Said yang memperlihatkan karakter bersifat kualitatif dilengkapi dengan pernyataan Abdul yang berbentuk kuantitatif. Keduanya menekankan bahwa CSO yang dipimpinnya layak diperhitungkan pemerintah dalam memperkuat praktik demokrasi di 
Indonesia.

Tiga aspek partisipasi RMI NU dan NU di atas memperlihatkan upaya untuk memperkuat demokratisasi di Indonesia. Keterlibatan CSO dalam melakukan pembangunan, melakukan pengawasan dan menyuarakan kepentingan kelompok di hadapan negara merupakan aspek penting dalam konsolidasi demokrasi. Keterlibatan CSO semacam itu diarahkan untuk membangun batasan bagi negara dalam menyelenggarakan pemerintahan agar tidak terjadi penyalahgunaan wewenang.

\section{Hambatan dan Tantangan Penyelengaraan LSN}

Hasil penelitian yang memperlihatkan kerja sama antara Kemenpora dengan RMI NU merupakan aspek yang tidak diprediksi sebelumnya. Kolaborasi keduanya menjadi temuan menarik sebab pada dasarnya pelaksanaan kompetisi sepak bola itu merupakan perwujudan dari tanggung jawab Kemenpora untuk melaksanakan Undang-Undang Republik Indonesia Nomor 3 tahun 2005 tentang Sistem Keolahragaan Nasional (UUSKN). Dalam regulasi itu, tercantum kewajiban pemerintah untuk melaksanakan pembinaan terhadap olahraga, termasuk pembinaan olahraga yang berlangsung di ranah pendidikan (Menteri Hukum dan Hak Asasi Manusia Republik Indonesia 2005:pasal 22). Secara teknis, mandat itu tertuang dalam Peraturan Pemerintah Republik Indonesia tahun 2007 tentang Penyelenggaraan Keolahragaan (PPPK). Ketika menghubungkan temuan dengan regulasi itulah aspek tidak terduga dari pengelolaan LSN ini muncul.

Dalam PPPK tertulis pedoman untuk melaksanakan pembinaan dan pengembangan olahraga pendidikan. Pada Pasal 26 Ayat 6 terdapat penjelasan bahwa pembinaan dan pengembangan olahraga menjadi menteri yang menyelenggarakan urusan pemerintahan di bidang pendidikan agama dilaksanakan bersama secara koordinatif dengan Menteri yang sesuai dengan ketentuan Peraturan Perundang-Undangan (Presiden Republik Indonesia 2007:12). Artinya untuk melakukan pembinaan dan pengembangan terhadap lembaga pendidikan pesantren, maka Kemenpora harus berkoordinasi dengan Kementrian Agama. Akan tetapi bentuk koordinasi semacam itu tidak pernah disinggung Menpora dalam launching LSN yang dilakukan pada tahun 2017.

Konsolidasi demokrasi yang dilakukan Menpora melalui penyelenggaraan LSN pada akhirnya menuai masalah. Permasalahan ini dipicu oleh hasil pemeriksaan yang Badan Pemeriksa Keuangan (BPK) pada tahun 2019. BPK menemukan sejumlah kejanggalan dalam pengelolaan dana yang dilakukan RMI. Dana yang bersumber dari Kemenpora itu ditengarai dikelola dengan cara yang tidak semestinya. BPK menemukan terdapat 2,04 miliar rupiah dana yang belum terserap pada Desember 2017. Seharusnya dana itu sudah harus digunakan untuk operasional LSN. Selain itu BPK juga menemukan transaksi yang dinilai fiktif sebesar 392 juta rupiah. Dengan demikian total dana yang ditengarai bermasalah sejumlah 2,4 miliar rupiah (Kresna 2019).

Abdul sebagai Ketua Ketua Panitia Nasional LSN menanggapi hasil

pemeriksaan tersebut. Abdul menjelaskan bahwa dana yang diterima dari 
Kemenpora terbagi menjadi dua termin. Pembagian fase pencairan itu berimbas pada panitia harus mencari 'dana talangan' untuk pembiayaan LSN tahun 2017. Setelah dana dari Kemenpora diperoleh secara keseluruhan, uang tersebut digunakan untuk mengganti dana pinjaman tersebut. Abdul menambahkan bahwa pihaknya harus mengembalikan uang sebesar 150 sampai 200 juta rupiah yang terbukti merupakan nota fiktif untuk penyediaan biaya transportasi dan akomodasi selama LSN. Pihak Kemenpora melalui asisten Deputi Pengembangan Olahraga Tradisional dan Layanan Khusus Kemenpora menyebut nominal yang berbeda dengan Rozzin, yaitu sekitar 300 juta rupiah yang harus dikembalikan ke kas negara. BPK juga memiliki versi sendiri tentang nominal yang harus dikembalikan pengelola LSN. BPK meminta RMI mengembalikan 2,4 milyar rupiah ke rekening negara (Kresna 2019).

BPK pada tahun 2019 merekomendasaikan LSN dihentikan pelaksanaannya. RMI NU mengabaikan rekomendasi itu dan tetap menyelenggarakan LSN dengan pembiayaan yang dilakukan secara mandiri. LSN tahun 2019 diselenggarakan RMI NU tanpa kerja sama dengan Kemenpora maupun Kementrian Agama. Peserta LSN mengalami penurunan di kompetisi mandiri itu. Jumlah region yang terlibat hanya sebanyak 28 dengan total peserta sejumlah 800 tim sepakbola dari berbagai pondok pesantren (Jabbar 2019). Di sisi lain, Menpora pada waktu itu juga terjerat kasus korupsi. Imam ditangkap KPK pada 18 September 2019 dengan tuduhan telah menerima uang sebanyak 26,5 miliar rupiah dari Komite Olahraga Nasional Indonesia (KONI). Berdasarkan atas kecurangan itu Imam dihukum tujuh tahun penjara dan denda sebanyak 400 juta rupiah (CNN Indonesia 2020).

Penyelenggaraan LSN pada tahun 2020 juga mengalami kendala yang krusial. Kendala itu tidak berhubungan dengan aspek adminsitratif atau pendanaan kompetisi itu. Pelaksanaan LSN di tahun itu harus terhenti bukan karena kolaborasi antara RMNI NU dengan Kemenpora yang dibatalkan. Penyelenggaraan LSN 2020 berdasarkan Surat Keputusan Panitia Nasional pada tanggal 28 September 2020 ditiadakan. Penyelenggaraan Seri Regional dan Seri Nasional LSN 2020 ditunda hingga tahun 2021 dengan mempertimbangkan perkembangan pandemi di Tanah Air.

\section{Kesimpulan}

Ternyata partisipasi civil society dalam program pembangunan pemerintah yang selama ini dibayangkan selalu memperkuat konsolidasi demokrasi tidak benar adanya. Konsolidasi demokrasi yang terjadi menurut penelitian ini lebih disebabkan oleh partisipasi dalam merumuskan dan implementasi kebijakan pemerintah serta penyaluran kepentingan CSO yang sesuai dengan regulasi. Partisipasi CSO dalam program-program pembangunan pemerintah tidak sertamerta mengarahkan praktik demokrasi menjadi lebih kuat. Apabila partisipasi dalam konsolidasi demokrasi dilakukan tanpa perencanaan yang matang, maka upaya itu justru akan memperlemah praktik demokrasi di negara Indonesia. Dengan demikian, prinsip konsolidasi itu tetap harus berdasarkan pada gagasan untuk menjadikan demokrasi sebagai the only game in the town. 
Mengingat krusialnya temuan penelitian ini, maka pembuat kebijakan perlu untuk merumuskan pola kolaborasi antara CSO dengan pemerintah. Kolaborasi antara CSO dengan pemerintah pada prinsipnya merupakan bagian penting dalam konsolidasi demokrasi. Apabila pola kolaborasi itu tidak dirancang dan diawasi secara saksama, maka kerja sama antara dua lembaga itu justru berpotensi untuk menjauhkan negara dari kondisi yang demokratis. Kerja sama antara CSO dengan pemerintah yang tidak terencana secara sistematis dapat menjadi ancaman baru bagi praktik demokrasi, terutama dengan adanya praktik korupsi, kolusi dan nepotisme. Maka dari itu, pemerintah dan CSO perlu menentukan pola kolaborasi yang dapat menyokong proses konsolidasi demokrasi secara menyeluruh.

Akan bermanfaat untuk melanjutkan penelitian tentang kolaborasi antara CSO dengan pemerintah dalam pelaksanaan pembangunan olahraga. Aspek ini perlu dipelajari lebih lanjut untuk menemukan kelebihan dan kelemahan kolaborasi antara CSO dan pemerintah dalam pembangunan negara. Temuan itu diperlukan untuk merumuskan pola kolaborasi antara kedua lembaga tersebut dalam menjalankan fungsi sebagai pilar-pilar utama dalam negara demokrasi. Dengan adanya temuan mengenai pola kolaborasi semacam itu, diharapkan proses kolaborasi antara CSO dengan pemerintah sebagai upaya untuk konsolidasi demokrasi akan berlangsung lebih berdaya guna. 


\section{Daftar Pustaka}

Arifa, Puji, dan Humas Jateng. 2018. "Perkuat Bangsa Lewat Olahraga." humas. jatengprov.go.id. Diambil (https://humas.jatengprov.go.id/detail_berita_ gubernur?id=1661).

Azra, Azyumardi, Dina Afrianty, dan Robert W. Hefner. 2007. "Pesantren and Madrasa: Muslim Schools and National Ideals In Indonesia." Hal. 172-98 in The culture and politics of modern Muslim education, diedit oleh R. W. Hefner dan M. Q. Zaman. Princeton and Oxford: Princeton University Press.

Bachrain, Ahmad. 2017. “Menpora Terus Gemakan Liga Santri Nusantara." CNNIndonesia.com. Diambil (https://www.cnnindonesia.com/ olahraga/20171120184440-178-256956/menpora-terus-gemakan-liga-santrinusantara).

Bruce, Steve dan Steven Yearly. 2006. The Sage Dictionary of Sociology. California: Sage Publication.

Claringbould, Inge dan Annelies Knoppers. 2008. “Doing and undoing gender in sport governance." Sex Roles 58(1-2):81-92.

CNN Indonesia. 2020. "Jejak Kasus Imam Nahrawi hingga Divonis 7 Tahun Penjara." CNNIndonesia.com. Diambil (https://www.cnnindonesia.com/ nasional/20200629202245-12-518793/jejak-kasus-imam-nahrawi-hinggadivonis-7-tahun-penjara).

Diamond, Larry Jay. 1994. "Toward Democratic Consolidation." Journal of Democracy 5(3):4-17.

van Dijk, Teun A. 2001. "Multidisciplinary CDA: a plea for diversity." in Methods of Critial Discourse Analysis, diedit oleh R. Wodak dan M. Meyer. London: Sage Publication.

Fakih, Mansour. 1999. "Masyarakat Sipil; Catatan Pembuka." Wacana: Jurnal Ilmu Sosial Transformatif 1.

Firdaus, Sandy. 2017. "Liga Santri Nusantara, Ajang Membentuk Pemain dan Pribadi Berkarakter." PanditFootbal.com. Diambil (https://www. panditfootball.com/cerita/210282/SFS/171024/liga-santri-nusantara-ajangmembentuk-pemain-dan-pribadi-berkarakter).

Giulianotti, Richard. 2011. “Sport, peacemaking and conflict resolution: a contextual analysis and modelling of the sport, development and peace sector." Ethnic and Racial Studies 34(2):207-28.

Giulianotti, Richard, Hannu Itkonen, Arto Nevala, dan Anna-Katriina Salmikangas. 2019. "Sport and civil society in the Nordic Region." Sport in Society 22(4):54054.

Griffin, Pat. 2012. "LGBT Equality in Sports: Celebrating our Successes and Facing our Challenges." Hal. 1-12 in Sexual orientation and gender identity in sport: Essays from activists, coaches, and scholars.

Hadi, Otho H. 2010. “Peran Masyarakat Sipil dalam Proses Demokratisasi." Makara: Sosial Humaniora 14(2):117-29. 
Hadiwinata, Bob Sugeng. 2005. “Civil Society: Pembangun dan Sekaligus Perusak Demokrasi." Jurnal Ilmu Sosial dan Ilmu Politik 9(1):1-22.

Harjo, Indhar Wahyu Wira. 2019. "Perebutan Pengaruh Antara Negara, Pasar, dan Masyarakat Sipil dalam Kasus Pelarangan Konvoi Aremania." Jurnal Sosiologi Nusantara 5(1):43-64.

Haryatmoko. 2016. Critical Discourse Analysis (Analisis Wacana Kritis): Landasan Teori, Metodologi dan Penerapannya. Jakarta: Rajawali Press.

Hefner, Robert W. 1993. "Islam, State, and Civil Society: ICMI and the Struggle for the Indonesian Middle Class." Indonesia 56(56):1.

Imam, Zamroni. M. 2007. “Jalan Terjal Transisi Demokarsi Relasi NegaraMasyarakat Menuju Konsolidasi Demokrasi." Unisia 30(63):39-49.

Ito, Takeshi. 2011. "Historicizing the power of civil society: A perspective from decentralization in Indonesia." Journal of Peasant Studies 38(2):413-33.

Jabbar, Abi Abdul. 2019. “800 Pesantren Ikuti Kompetisi Liga Santri Nusantara 2019." madaninews.id. Diambil (https://www.madaninews.id/8218/800pesantren-ikuti-kompetisi-liga-santri-nusantara-2019.html).

Kartodirdjo, Sartono. 1997. "Metode Penggunaan Bahan Dokumen." in MetodeMetode Penelitian Masyarakat, diedit oleh Koentjaraningrat. Jakarta: Gramedia Pustaka Utama.

Kaufman, Peter dan Eli A. Wolff. 2010. "Playing and Protesting: Sport as a Vehicle for Social Change." Journal of Sport and Social Issues 34(2):154-75.

Kilcline, Cathal. 2017. "Sport and Protest: Global Perspectives." The International Journal of the History of Sport 34(3-4).

Kresna, Mawa. 2019. “Kejanggalan Pengelolaan Duit Liga Santri 2017.” tirto.id. Diambil (https://tirto.id/kejanggalan-pengelolaan-duit-liga-santri-2017df3D).

Kurniawan, Dian. 2015. “Berantas Radikalisme, Menpora dan PBNU Gelar Liga Santri." liputan6.com. Diambil (https://www.liputan6.com/news/ $\mathrm{read} / 2285764$ / berantas-radikalisme-menpora-dan-pbnu-gelar-liga-santri).

Linz, Juan J. 1996. Problems of Democratic Transition and Consolidation. London: The John Hopkins University Press.

Menteri Hukum dan Hak Asasi Manusia Republik Indonesia. 2005. UndangUndang Republik Indonesia Nomor 3 Tahun 2005 Tentang Sistem Keolahragaan Nasional. Indonesia.

Mercer, Claire. 2002. "NGOs, civil society and democratization: A critical review of the literature." Progress in Development Studies 2(1):5-22.

Nugroho, Kris. 2001. “Konsolidasi demokrasi.” Jurnal Masyarakat, Kebudayaan, dan Politik Masyarakat(2):25-34.

Presiden Republik Indonesia. 2007. Peraturan Pemerintah Republik Indonesia Nomor 16 tahun 2007 tentang Penyelenggaraan Keolahragaan. Indonesia.

Priyatna, Yana. 2020. "Rihlah Ilmiah dan Kitabah dalam Tradisi Intelektualisme Islam Nusantara." Muqoddima: Jurnal Pemikiran dan Riset Sosiologi 1(1). 
Syarif, M. 2019. "Politik Etis Pemerintah Kolonial Hindia." Inovatif 5(1):109-31.

Towler, Christopher C., Nyron N. Crawford, dan Robert A. Bennett. 2020. "Shut Up and Play: Black Athletes, Protest Politics, and Black Political Action." Persprectives on Politics 18(1):111-27.

Usman, Sunyoto. 2002. "Civil Society di Indonesia: Suatu Tantangan." Jurnal Ilmu Sosial dan Ilmu Politik 5(3). 


\section{Pedoman Penulisan}

Naskah artikel ditulis dalam bahasa Indonesia atau bahasa Inggris dengan panjang 5000-8000 kata. Lebih dari 8000 kata ditoleransi dengan catatan bahwa kelebihan tersebut sepadan dengan data, informasi, serta analisis dan diskusi yang dikerjakan. Naskah merupakan hasil penelitian maupun refleksi kritis atas sebuah pemikiran, teori, atau metodologi dalam sosiologi atau ilmu sosial secara umum. Penting diingat bahwa naskah yang diajukan tidak tengah dalam proses pengajuan atau dalam proses telaah (review) di jurnal lain. Pengajuan naskah artikel dilakukan melalui menu submission (pengajuan) di website http://journal.unusia.ac.id/index.php/Muqoddima.

Naskah ditulis dengan menggunakan font Book Antiqua pada program Microsoft Word, dengan ekstensi .doc, .docx, atau .rtf. Sistem penulisan secara umum adalah sebagai berikut:

\section{Judul}

Judul merefleksikan isi tulisan, singat, padaat dan diupayakan menarik minat pembaca. Font sebesar 20 poin, dengan huruf kapital di depan setiap kata (Capitalized Each Word) kecuali kata sambung. Panjang judul tidak lebih dari 10 kata. Hindari menggunakan tanda kurung (...) dalam judul.

\section{Nama dan identitas penulis}

Nama lengkap penulis dicantumkan tanpa gelar akademik, disertai keterangan institusi dan alamat email.

\section{Abstrak dan kata kunci}

Abstrak ditulis dalam bahasa Indonesia dan bahasa Inggris dengan panjang antara 150-250 kata. Abstrak seutuhnya ditulis dalam bentuk naratif memuat kajian, tujuan penelitian, metodologi, temuan, dan argumentasi. Kata kunci maksimal terdiri atas 6 (enam) kata/frasa.

\section{Tubuh artikel}

Tubuh artikel ditulis dengan ukuran huruf 11 poin, kecuali untuk sub judul (13 poin) dan catatan kaki (10 poin). Setiap awal paragraf ditulis menjorok ke dalam sepanjang 1 $\mathrm{cm}$. Penggunaan kata-kata asing dituliskan secara miring (italic). Tubuh artikel memuat empat komponen pokok meliputi (1) pendahuluan, (2) metode/cara kerja, (3) analisis dan diskusi, dan (4) kesimpulan.

\section{Catatan kaki}

Catatan kaki dituliskan hanya jika diperlukan, yakni untuk memberikan keterangan tambahan atasu suatu hal spesifik yang tidak sinambung secara langsung bila diletakkan sebagai bagian tubuh artikel. Hindari menggunakan catatan kaki jika berkenaan dengan sumber rujukan teoritis atau sumber data primer.

\section{Daftar Pustaka}

Daftar Pustaka ditulis dengan mengikuti standar format ASA (American Sociological Association). Format ASA juga berlaku dalam penulisan kutipan di tubuh artikel, termasuk 
catatan perut dan catatan kaki (note, footnote).

Berikut ini adalah berapa contoh penulisan isi Daftar Pustaka:

Andreassen A., Bard. 2007. "Human Rights and Legal Empowerment of the Poor", Extreme Poverty and Human Rights Expert Seminar, Geneva 23-24 February 2007, Norwegian Centre for Human rights, University of Oslo.

Fatoni, Muhammad Sulton. 2015. Kapital Sosial Pesantren (Studi Tentang Komunitas Pesantren Sidogiri Pasuruan Jawa Timur). Jakarta: Universitas Indonesia.

Geertz, Clifford. 1965. "Religion: Anthropological Study", dalam David L. Sills (ed.) International Encyclopedia of the Social Sciences. London: Collier-Macmillan Publishers.

Jones, Bobby L., Daniel S. Nagin, dan Kathryn Roeder. 2001. “A SAS Procedure Based on Mixture Models for Estimating Developmental Trajectories." Sociological Methods and Research 29 (3):374-93. Diakses pada 26 April 2005 (https://journals.sagepub. com/doi/10.1177/0049124101029003005).

Kukathas, Chandran. 2002. "Multiculturalism as Fairness: Will Kymlicka's Multicultural Citizenship." Journal of Political Philosophy 5(4):406-427. Diakses pada 27 Mei 2019. (https://onlinelibrary.wiley.com/doi/10.1111/1467-9760.00041)

Keterangan lebih rinci terkait ketentuan penulisan dapat diperiksa dalam Template Artikel MJPRS. 


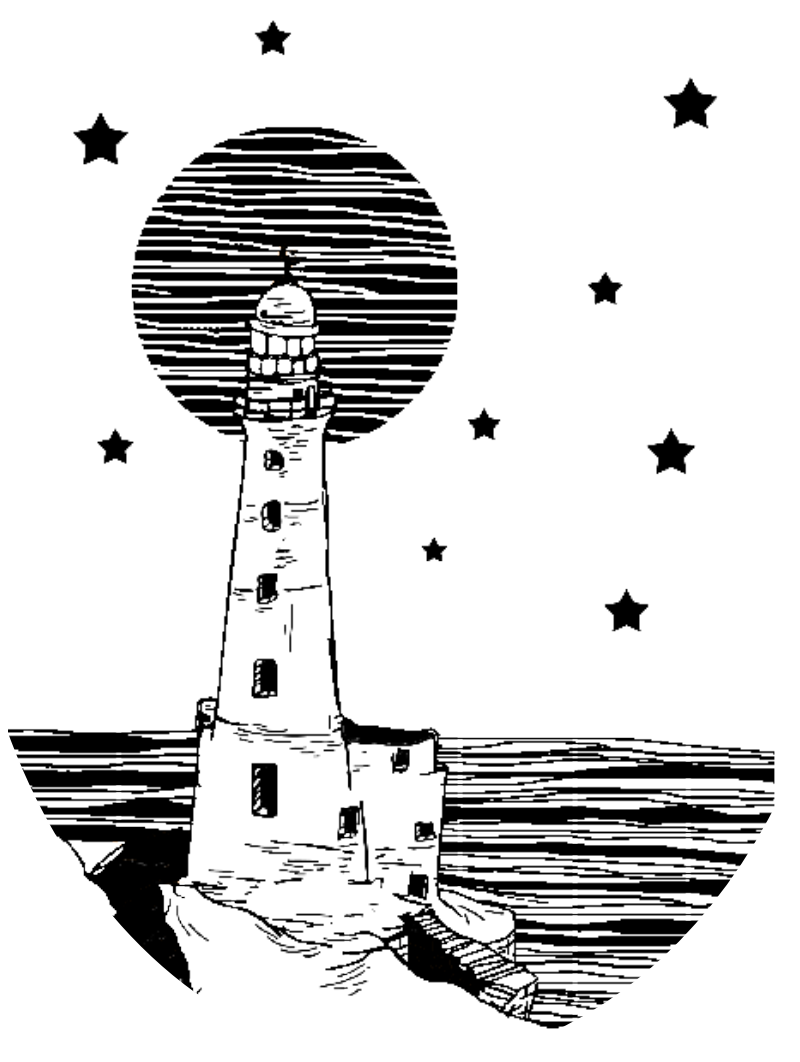



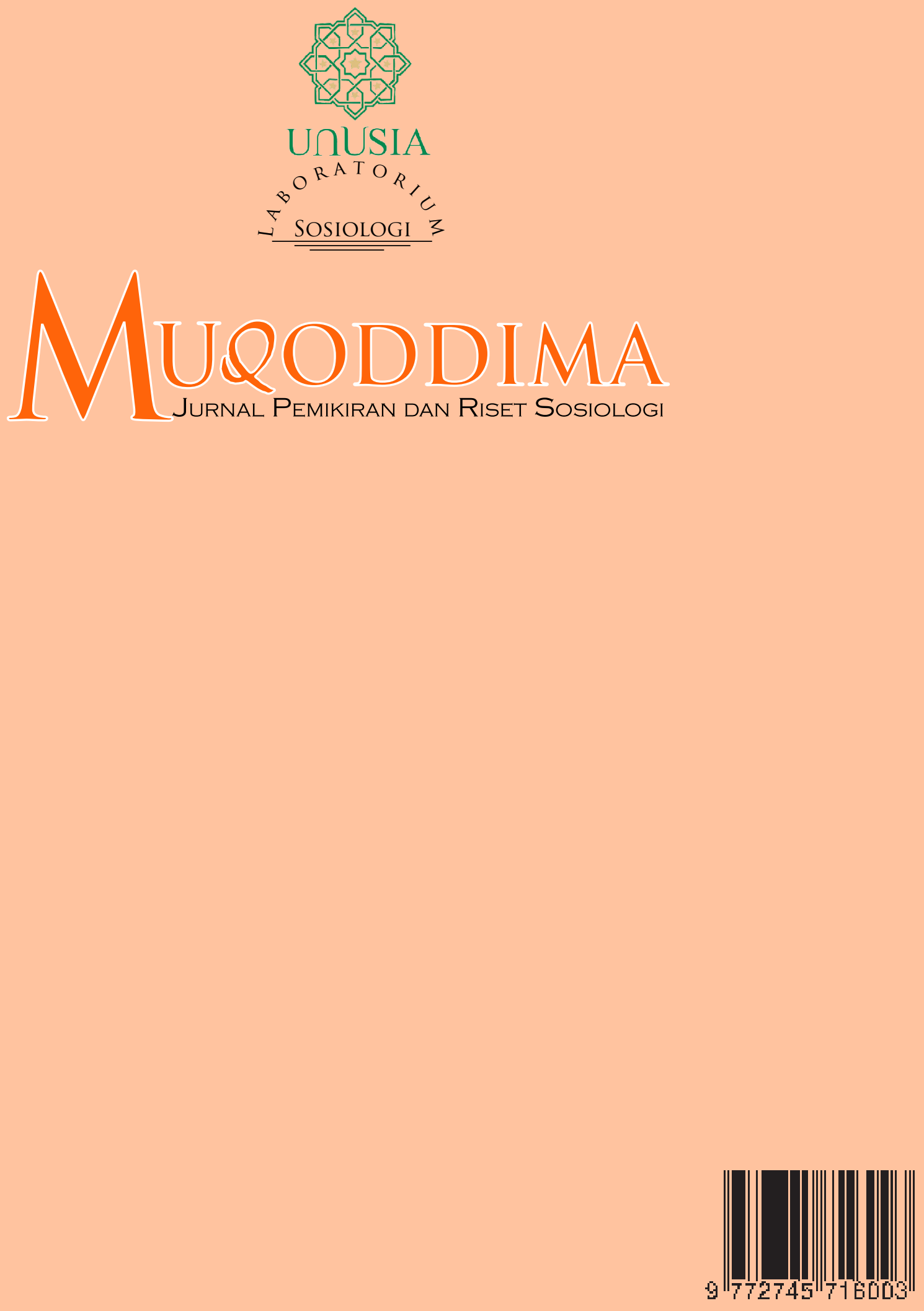